IJICIS, Vol.20, No.2, 32-52

DOI: 10.21608/ijicis.2020.48148.1037

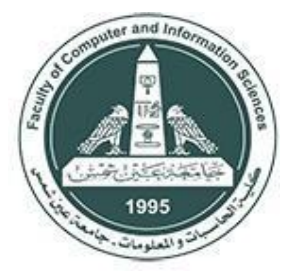

\title{
International Journal of Intelligent Computing and
} Information Sciences

https://ijicis.journals.ekb.eg/

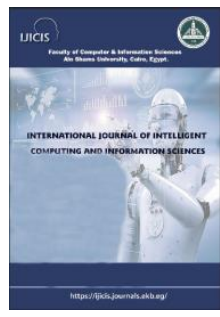

\section{LEARNING PREFERENCES ADAPTATION BASED ON THE PERSONALIZED ADAPTIVE GAMIFIED E-LEARNING (PAGE) MODEL}

\author{
Yara Maher \\ Department of Software \\ Engineering and Information \\ Technology, Faculty of Engineering \\ and Technology, \\ Egyptian Chinese University \\ Cairo 11351, Egypt \\ ymaher@ecu.edu.eg \\ Sherin M. Moussa* \\ Department of Information \\ Systems, Faculty of Computer and \\ Information Sciences, \\ Ain Shams University \\ Cairo 11566, Egypt \\ sherinmoussa@cis.asu.edu.eg \\ Received 2020-08-25; Revised 2020-9-16; Accepted 2020-10-06 \\ Available online 2020-12-26
}

\author{
M. Essam Khalifa \\ Department of Software \\ Engineering and Information \\ Technology, Faculty of Engineering \\ and Technology, \\ Egyptian Chinese University \\ Cairo 11351, Egypt \\ khalifa@ecu.edu.eg
}

\begin{abstract}
Many studies have addressed e-learning, aiming to create a platform for the learning process that completes the traditional classroom work and maximizes the effectiveness of learning outcomes. Gamifying personalized adaptable educational systems have been recently considered to keep the learners motivated and positively progressing in a flow state. However, the current models remain inadequate, providing limited resources for comprehensive learning analytics. In this paper, a theoritical learning preferences adaptation model is proposed based on the Personalized Adaptive Gamified E-learning (PAGE) model. The PAGE model supports blended learning by enforcing the engagement of the traditional learning process's parties, where effective learning analytics can be sustained to continuously improve the quality of the learning experience. The overall model has been evaluated for its validity through a survey from different perspectives. The overall mean value of the evaluation is 2.77 out of 3 . Thus, the evaluation outcomes for the adaptation, gamification, and learning experience of the PAGE model ensure a promising vision for advancements in the learning processes and analytics.
\end{abstract}

Keywords: educational systems, preferences adaptation, learning preferences, elearning, clustering.

\footnotetext{
* Corresponding author: Sherin M. Moussa

Department of Information Systems, Faculty of Computer and Information Sciences

E-mail address: sherinmoussa@cis.asu.edu.eg
} 


\section{Introduction}

Technology has widely influenced various fields, including education, with the intention of utilizing resources to overcome any shortage in the service quality, learning outcomes, and productivity (Almohammadi, Hagras, Alghazzawi, \& Aldabbagh, 2017; Amin, A. E. 2019). Accordingly, the classroom learning experience has been upgraded to be computer/internet-based, commonly known as e-learning. Elearning employs the technological advances to serve the educationsal process by digitizing the learning material and allowing them to be available with the flexibility of time, budget, and location, with no limitation to the instructor manpower (Tseng, Cheng, \& Yeh, 2019; Shabana, B. T. 2019). E-learning systems may also support blended learning. Thus, merging the advantages of e-learning with the classroom experience, so learners can move with their own pace, unlike traditional learning (Asarta \& Schmidt, 2017; Boelens, Voet, \& Wever, 2018; Erkens \& Bodemer, 2019; Owston \& York, 2018; Yip, Wong, Yick, Chan, \& Wong, 2019). Reviewing the standard educational process, three major fundamentals have been emphasized; designing the course structure, teaching, and evaluating the achievement of learning outcomes (Jung, Kim, Yoon, Park, \& Oakley, 2019; Petri \& Wangenheim, 2017; Elabnody, M., Fouad, M., Maghraby, F., \& Hegazy, A. 2017). The instructional design for the educational process can be further detailed into seven steps as illustrated in Figure 1. If an adaptation is required at any step, the process will start iterating from that step while applying the necessary modifications. The step of instructional feedback reflects the learner's performance, acting as the bridge between the learner's current and desired knowledge level (Chen, Breslow, \& Deboer, 2018). It serves the learner in many ways, including the clarification of learning outcomes, identifying learner's learning shortages, and pushing him/her to strive upgrading his/her performance (Clark-gordon, David, Hadden, \& Frisby, 2019; Daradoumis, Manuel, Puig, Arguedas, \& Calvet, 2019).

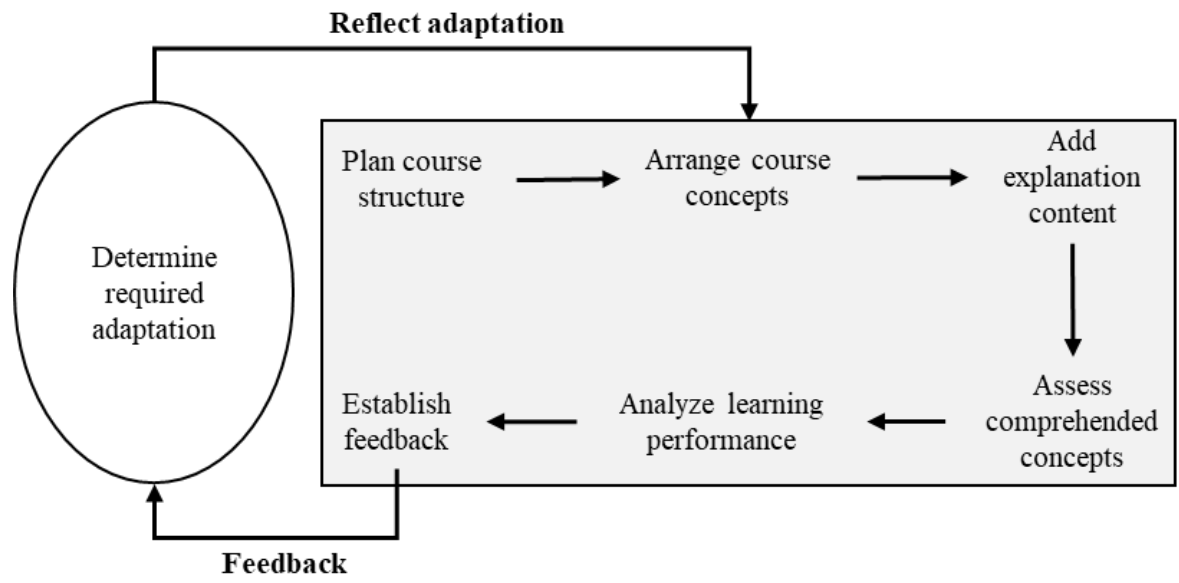

Figure 1: The concluded instructional design model

Adaptation is the capability of e-learning systems to further utilize the technological advances for personalizing the educational content presented to the learner through measurable parameters (Dominic et al., 2015). This can be carried out by three steps; The first step is to continuously gather data about the learner's learning progress and preferences, acquiring the needed parameters to create an initial start point for him/her. The second step is to utilize these data in order to appropriately present educational material for that individual learner, and lastly, is to gather feedback about the learning process performance through 
tracking his/her behavior to further adapt and accustom the educational process in order to attain personalized learning experience (Akbulut \& Cardak, 2012; Anouar Tadlaoui, Aammou, Khaldi, \& Novaes Carvalho, 2016; Chen et al., 2018; Dominic et al., 2015; Jumaa, Moussa \& Khalifa, 2017; Kyewski \& Krämer, 2018).

Therefore, adapting the educational process is not a simple defined action, since it involves adapting one or more aspects of the education process, ranging from the learning content, learning path, teaching strategies and activities for content delivery, learning assessment, etc. Thus, many types of learning adaptation have been emerging, i.e. learning flow-based adaptation, content-based adaptation, evaluation adaptation, etc. (Burgos, Tattersall, \& Koper, 2007). They represent the learner's preferred way to receive and process the information presented, and to stay engaged in the learning process, described as the learner's learning style (Alzain, Clark, Jwaid, \& Ireson, n.d.; T. Hsu, 2017). Many learning style models have been proposed to define the learner's preferences, having the Felder Silverman Learning Model (FSLM) the most common (Dominic et al., 2015; Sivaranjani, Agalya, Kowsalya, \& Sivasankari, 2016). The FSLM states that the learner's preferences are classified into four dimensions; perception, input, processing, and understanding/ thinking, where each dimension describes the learner in terms of one of two adverse poles (R. Felder \& Silverman, 1988). Accordingly, adaptation emphasizes on developing learning materials that should match the learner's poles as much as possible, which implies that each learning content may be developed in many teaching styles that suit different learning styles, with different combinations of learning style's poles (Wang \& Wu, 2011). Thus, learning objects (LOs), or Open Electronic Resources (OERs), have been introduced to represent learning materials that can be widely shared, reused and modified, where the Sharable Content Object Reference Model (SCORM) has been defined to manage digitized content of LOs (ADL, 2003; Yassine, Kadry, \& Sicilia, 2017). Previous studies have arisen the eager demand to fulfil an expanding gap in current e-learning systems. Some studies considered adaptation only, while others focused on gamification solely. A certain course was specifically manipulated, with partial adoptions of the instructional design process. When both adaptation and gamification were addressed, a static game was developed, ignoring sharable LOs. However, learning preferences adaptation after each learner's interaction in the learning process was not addressed. Therefore, the gap aimed to be overcome in this paper is as follows:

"How can learning analytics results be utilized in a way that learners' learning experience keeps getting more personalized as the learner prefer"

This paper focuses on the adaptation following the Personalized Adaptive Gamified E-learning (PAGE) model (Y.Maher, S.Moussa, \& E.Khalifa, 2020). A theoritical learning preferences adaptation model is proposed based on the PAGE model. It relies on the learning analytics created to perform necessary learning preferences adaptation, utilizing the learning analytics results to make the necessary adaptation based on the decision made. The rest of the paper is organized as follows. Section 2 presents the related work of this study, Section 3 summarizes the PAGE model, and then comes section 4 that displays the proposed learning preferences adaptation model. Finally, section 5 concludes the study and highlights future work. 


\section{Related Work}

An educational experience should be both adaptable and enjoyable to each individual learner. Some studies have focused on adaptable educational process, while others have only considered gamifying it. Other studies have based the adaptation on learning styles, whereas some of them have partially adopted certain dimensions of these models. In this section, we explore the main works that have been proposed to introduce the adaptation and gamification perspectives into the educational systems. Table 1 summarizes the main concepts that have been addressed in the reviewed studies with respect to the proposed PAGE model to emphasize the main contributions of this study.

A conceptual model for adaptive intelligent tutoring systems was proposed in (Phobun \& Vicheanpanya, 2010). It consisted of an expert model that compares the learner's actions and selections with the expected performance, which allowed to adapt the learning process accordingly. Although it was domainindependent, and the adaptation was based on the learning style of the learner, the presentation and navigation (learning path/flow) adaptation types were adopted, neglecting the adaptation to other learning styles' dimensions. Moreover, the course structure details, in terms of sharable reusable LOs, were not addressed. Thus, no modification could be applied on the course structure level. In addition, there was no explicit mentioning of the evaluation and feedback processes by which adaptation takes place.

The hypermedia adaptation based on learning styles was addressed in (Anouar Tadlaoui et al., 2016), which mainly focused on the learner model for the presentation and navigation adaptation. The learner model consisted of two components: the performance model that stored the learner's behavior during the learner process, and the learning history model that stored previous learner's knowledge and interactions with the interface. Other educational process's steps like course planning and concepts division, specific learning style, adaptation on course planning or LOs level were never mentioned.

Table 1. Summary of the investigated studies

\begin{tabular}{|c|c|c|c|c|c|c|c|}
\hline Authors & $\begin{array}{c}\text { Educational } \\
\text { process }\end{array}$ & $\begin{array}{l}\text { Interacting } \\
\text { Entities }\end{array}$ & $\begin{array}{c}\text { Learning } \\
\text { Style- } \\
\text { based? }\end{array}$ & $\begin{array}{c}\text { Considered } \\
\text { LOs / OERs? }\end{array}$ & $\begin{array}{l}\text { Gamification- } \\
\text { based? }\end{array}$ & $\begin{array}{l}\text { Adaptation- } \\
\text { based? }\end{array}$ & $\begin{array}{c}\text { Combined } \\
\text { Adaptation \& } \\
\text { Gamification? }\end{array}$ \\
\hline $\begin{array}{l}\text { Phobun and } \\
\text { Vicheanpanya }\end{array}$ & $\begin{array}{c}\text { Feedback is } \\
\text { neglected }\end{array}$ & Learner & Generic & - & - & $\begin{array}{l}\text { Interface and } \\
\text { learning path }\end{array}$ & - \\
\hline $\begin{array}{c}\text { Anouar } \\
\text { Tadlaoui et } \\
\text { al. }\end{array}$ & $\begin{array}{l}\text { Course structure } \\
\text { was neglected }\end{array}$ & Learner & Generic & - & - & $\begin{array}{l}\text { Interface and } \\
\text { learning path }\end{array}$ & - \\
\hline $\begin{array}{l}\text { Kahraman, } \\
\text { Sagiroglu, } \\
\text { and Colak }\end{array}$ & $\begin{array}{c}\text { Feedback is } \\
\text { neglected }\end{array}$ & $\begin{array}{l}\text { Domain } \\
\text { Expert, } \\
\text { Learner }\end{array}$ & Generic & $\begin{array}{l}\text { Not exactly, } \\
\text { but divided } \\
\text { the course } \\
\text { into topics } \\
\text { and goals }\end{array}$ & - & $\begin{array}{c}\text { Content, } \\
\text { Interface and } \\
\text { learning path }\end{array}$ & - \\
\hline $\begin{array}{l}\text { Dominic and } \\
\text { Francis }\end{array}$ & $\begin{array}{l}\text { All steps were } \\
\text { considered }\end{array}$ & Learner & Generic & $\sqrt{ }$ & - & $\begin{array}{l}\text { Fitting the } \\
\text { learning style } \\
\text { dimensions }\end{array}$ & - \\
\hline $\begin{array}{l}\text { Ferrer and } \\
\text { Kirschning }\end{array}$ & $\begin{array}{l}\text { All steps were } \\
\text { considered }\end{array}$ & Learner & FSLM & - & - & $\begin{array}{l}\text { Fitting the } \\
\text { learning style } \\
\text { dimensions }\end{array}$ & - \\
\hline $\begin{array}{l}\text { Dominic, } \\
\text { Britto, and } \\
\text { Francis }\end{array}$ & $\begin{array}{l}\text { All steps were } \\
\text { considered }\end{array}$ & Learner & Generic & $\sqrt{ }$ & - & $\begin{array}{c}\text { Content, } \\
\text { Interface and } \\
\text { learning path }\end{array}$ & - \\
\hline
\end{tabular}




\begin{tabular}{|c|c|c|c|c|c|c|c|}
\hline Yang & $\begin{array}{l}\text { Assessment } \\
\text { without } \\
\text { explanation }\end{array}$ & Learner & - & - & $\begin{array}{c}\text { Competition } \\
\text { mechanism is not } \\
\text { supported, static } \\
\text { game }\end{array}$ & - & - \\
\hline Chang et al. & $\begin{array}{l}\text { Assessment } \\
\text { without } \\
\text { explanation }\end{array}$ & Learner & - & - & $\begin{array}{c}\text { Competition } \\
\text { mechanism is not } \\
\text { supported, static } \\
\text { game }\end{array}$ & - & - \\
\hline $\begin{array}{c}\text { Erhel and } \\
\text { Jamet }\end{array}$ & $\begin{array}{c}\text { Course structure } \\
\text { was neglected }\end{array}$ & Learner & - & - & Static game & - & - \\
\hline $\begin{array}{l}\text { G. J. Hwang, } \\
\text { Wu, and } \\
\text { Chen }\end{array}$ & $\begin{array}{l}\text { Course structure } \\
\text { was neglected }\end{array}$ & Learner & - & - & Set of mini games & - & - \\
\hline $\begin{array}{c}\text { Ildephonce, } \\
\text { Mugisa, \& } \\
\text { Allen }\end{array}$ & $\begin{array}{c}\text { Considered } \\
\text { structure of each } \\
\text { individual LO }\end{array}$ & Learner & - & $\sqrt{ }$ & Generic Game & - & - \\
\hline $\begin{array}{c}\text { Soflano, } \\
\text { Connolly, and } \\
\text { Hainey } \\
\end{array}$ & $\begin{array}{l}\text { Course structure } \\
\text { was neglected }\end{array}$ & Learner & FSLM & - & Static game & $\begin{array}{l}\text { Fitting the } \\
\text { learning style } \\
\text { dimensions }\end{array}$ & $\sqrt{ }$ \\
\hline $\begin{array}{l}\text { G.-J. Hwang } \\
\text { et al. }\end{array}$ & $\begin{array}{l}\text { Course structure } \\
\text { and feedback } \\
\text { were neglected }\end{array}$ & Learner & $\begin{array}{l}\text { Covered } \\
\text { only one } \\
\text { dimension } \\
\text { of FSLM }\end{array}$ & - & Static game & $\begin{array}{l}\text { Adaptation to } \\
\text { one learning } \\
\text { style } \\
\text { dimension }\end{array}$ & $\sqrt{ }$ \\
\hline $\begin{array}{c}\text { The PAGE } \\
\text { Model }\end{array}$ & $\begin{array}{c}\text { All educational } \\
\text { process steps are } \\
\text { considered }\end{array}$ & $\begin{array}{l}\text { Learner, } \\
\text { Domain } \\
\text { Expert, and } \\
\text { Supervisor }\end{array}$ & $\begin{array}{c}\text { Learning } \\
\text { style-type } \\
\text { independent }\end{array}$ & $\begin{array}{c}\text { Concepts are } \\
\text { expressed as } \\
\text { LOs }\end{array}$ & $\begin{array}{c}\text { Game type- } \\
\text { independent. } \\
\text { Game mechanics } \\
\text { and dynamics are } \\
\text { applied }\end{array}$ & $\begin{array}{l}\text { Fitting the } \\
\text { learning style } \\
\text { dimensions, } \\
\text { knowledge, } \\
\text { and skill levels }\end{array}$ & $\begin{array}{l}\text { Both concepts } \\
\text { are combined }\end{array}$ \\
\hline
\end{tabular}

In (Kahraman, Sagiroglu, \& Colak, 2013), the course was divided into topics and related goals, allowing the domain model to be domain-independent. It also included a supervision model, which in turn collected data from both the domain and user models to form an evaluation on the learning process for adaptation. However, neither a feedback method on the assessment objects nor modifying the course structure were mentioned. Another domain-independent model was proposed in (Dominic \& Francis, 2015) that adopted LOs. Different LO types were created to fit various learning styles, where the adaptation process presented the learner with a personalized content, consisting of suitable LOs that match the learner's learning style. However, the adaptation types that were based on the learning style were not discussed. Thus, no course or LO adaptation was referred to. (Ferrer \& Kirschning, 2014) purely focused on analyzing the learner's learning style. The authors discussed domain independency and learning style-based adaptations in terms of defining different combinations of learning styles' dimensions and presenting them through the suitable content. However, the adaptation types and the content structure were not considered.

A learning-based adaptive model was presented in (Dominic et al., 2015), in which the content was a group of LOs and the learners can give feedback accordingly. However, there was no engagement for a domain expert with the e-learning process to adapt the course structure or prerequisites. In addition, the relationships between the LOs were not supported. Moreover, although the adaptation was based on the learner's preferences and performance, the model did not present a tracking method for the learner's behavior. As discussed, these studies mainly lack the motivation factor, ignoring the elements pertaining to make the learning process more enjoyable and encouraging to continue the course. This can be overcome by adding gamification as a motivation factor for a game-themed learning experience, with attractive fictional background stories. 
A learning preferences-based adaptive game was developed by (Soflano, Connolly, \& Hainey, 2015b) to teach SQL. The game adaptation was based on the learner's learning preferences to modify the game difficulty level, content, presentation, and game controls. It has fully utilized the background fictional story as an important game mechanic, allowing learners to adapt their avatar. Thus, it considered the element of motivation by making the learning process more enjoyable. The story was historical-themed, where each mission required retrieving something from the fictional database. However, the game was domainspecific, in which neither LOs nor generic course structure and planning have been considered. Therefore, no adaptation can be made on the course structure or the exercises/LOs level. Moreover, it lacked applying the complete educational process steps. (G.-J. Hwang et al., 2012) developed an adaptive game, based on the learner's learning style. They adopted the global-sequential dimension of FSLM only. Thus, the game was adapted to the learner's preferred way to proceed in the learning path. In addition, the game adapted the content difficulty and skills level, but no adaptation to the course structure or presentation was discussed. Although the game contained a database for the learning material, there was no mention on how the course structure was developed. Therefore, the game did not fully support feedback, as a main step in the educational process.

\section{The PAGE Model}

The PAGE model proposed a framework for a fully adaptable e-learning system that extends Massive Open Online Courses (MOOCs) (Y.Maher, S.Moussa, \& E.Khalifa, 2020). The model engages course designers, teachers/parents, and learners into the learning process. The adaptation proposed included course structure adaptation, content adaptation, content selection adaptation, and learners' portfolio adaptation. To perform such adaptations, learning analytics system was created for decision support on the adaptation required. As clarified in (Y.Maher, S.Moussa, E.Khalifa, 2020) in further detail, the PAGE Model considers several repositories in order to provide a comprehensive learning feedback analysis as discussed below.

\subsection{The PAGE Repositories}

The PAGE model has three repositories, in which the data are constantly updated. The repositories Course and LOs Metadata and Learner Portfolio are filled prior and during the learning process, while the Learning Behavior and Feedback repository stores data after the learning process has begun and the learner was presented with the LOs. Figure 2 illustrates the content for each repository as follows: 


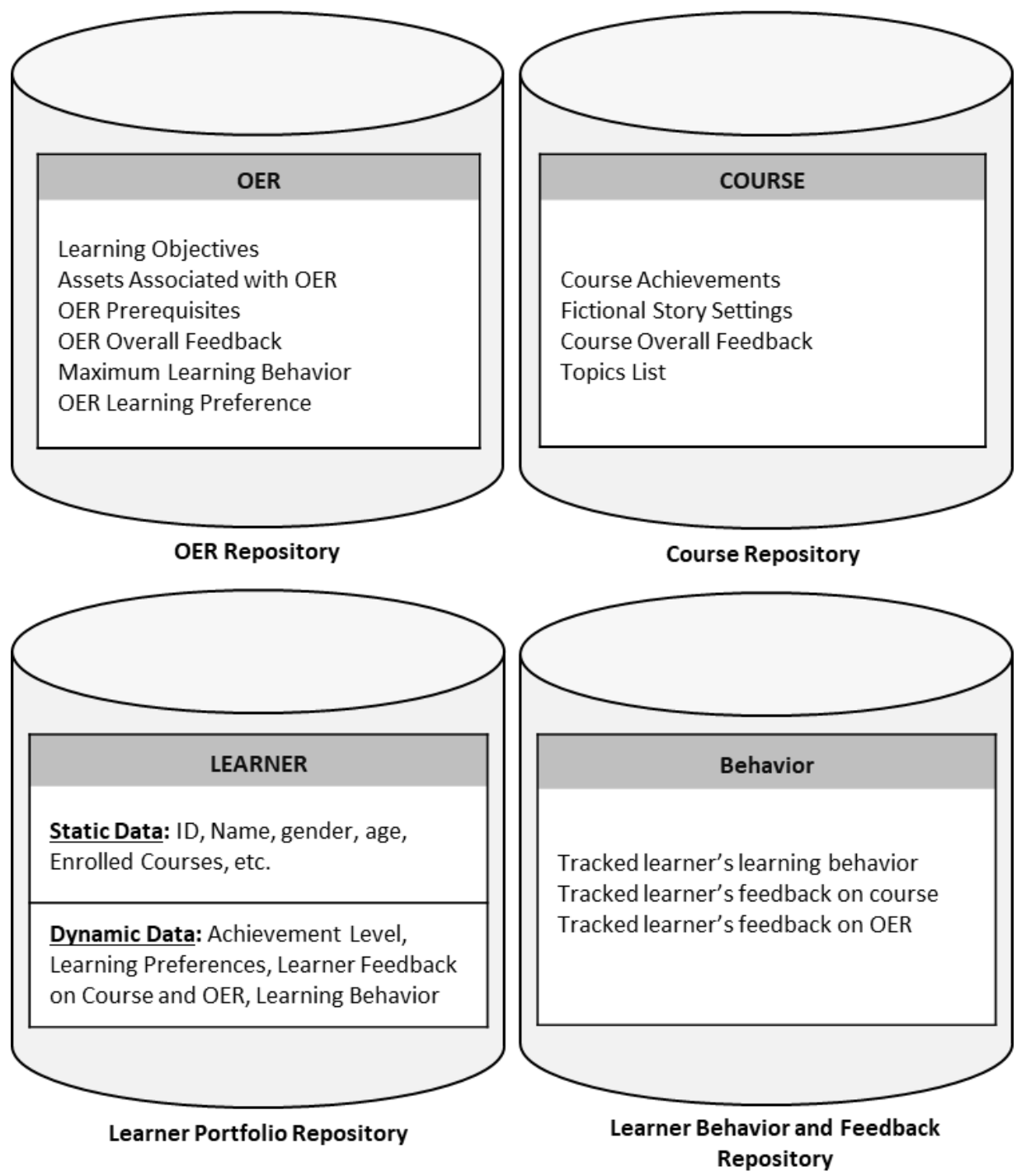

Figure 2: The repositories of the PAGE model

1. OER Repository: This repository interacts with the PAGE model before, during, and after the learning process, where it stores the specifications of the developed OERs. This includes the course OERs, learning objectives, assets, OERs feedback, learning preferences learning behavior parameters specified by the course designer.

2. Course Repository: This repository interacts with the PAGE model before, during, and after the learning process, where it stores the specifications of the developed course such as achievements, fictional story settings, the course overall feedback, and list of topics.

3. Learner Portfolio Repository: This repository stores the learner's static and dynamic data. The learner's static data are the basic data that defines the learner, like the learner's name, date of birth, etc. The dynamic data include data that are constantly adapted, like the learner's learning preferences, level of achievements and learning preferences. Another data that are linked to each course include learner's feedback on course and/or OERs. 
4. Learning Behavior and Feedback Repository: The role of this repository comes after the learning process has started and the learner begins playing his/her first OERs. The tracked learner's behavior after each OER is sent to this repository to be further analyzed by the following steps.

\subsection{The PAGE Model Evaluation}

In (Y.Maher, S.Moussa, \& E.Khalifa, 2020), a survey was conducted to consider the course designers' point of view on the PAGE model. The survey results were analyzed from two perspectives, evaluating categories perspectives, and PAGE module perspectives. The results are further discussed below:

The Instructional Design Steps Evaluating Category: This perspective has been investigated by five items related to how the instructional design steps are applied in the PAGE model. As presented in Figure 3(a), item 4 (Does the model analyze the learner's performance which in turn forms feedback on the learning object/course quality?) has the highest mean $(\mu=2.87, \sigma=0.032)$. This item got 2 responses for the 'Disagree' choice, indicating that the tracking and analyzing of learner's performance was effectively and clearly applied in the PAGE model. Thus, the learning style analysis, LOs selection, and learning behavior tracking processes have best confirmed their positive effects. Then comes item 2 of mean $(\mu=2.82$, $\sigma=0.454)$, which is slightly lower than item 4 , followed by item $1(\mu=2.76, \sigma=0.534)$ and $5(\mu=2.76$, $\sigma=0.474$ ) that have similar mean values. Item 3 (Does the model guide the domain expert to create achievements/ milestones when it is appropriate within the course structure?) comes last with the lowest mean value $(\mu=2.69, \sigma=0.534)$, which is related to the locating of milestones in the course structure. This is probably due to the weak practicing of some participants for applying the game mechanics into the course development process, in terms of identifying goals and achievements.

The Adaptation Evaluating Category: This evaluating category has been evaluated by four items to reflect how ideal the impact of adopting the adaptation concept is in the PAGE model. As shown in Figure 3(b), item 9 (Does presenting the course concepts as a set of learning objects allow them to be reused and modified independent of the course structure?) has relatively the highest mean value ( $\mu=2.87, \sigma=0.415)$. This item got 4 responses for the 'Disagree' choice, implying that the adoption and continuous adaptation of the learning objects effectively save effort and time of redeveloping independent content. Items 6 came second $(\mu=2.81, \sigma=0.427)$, then item $7(\mu=2.78, \sigma=0.462)$, whereas item 8 (Does the model allow for adapting the rewarding mechanism for a learning object?) has the lowest mean value ( $\mu=2.60, \sigma=0.652)$, with 31 responses for 'I'm not sure'. This is probably because the rewarding mechanism is still another unpracticed game mechanics concept, in which 31 unsure choices indicate that some participants are unfamiliar with the concept to decide its effective adoption in the proposed model.

The Gamification Evaluating Category: Three items have been explored to reflect the importance and effectiveness of importing gamification into the proposed PAGE model. As shown in Figure 3(c), item 11 (Does the model support the presentation of the learner's status and achievements?) has the highest mean value ( $\mu=2.80, \sigma=0.483$ ), emphasizing the proper application of the leaderboard in the proposed model, which is considered as a competition mechanism of the game mechanics, followed by item $10(\mu=2.66$, $\sigma=0.606$ ). However, item 12 (Do the achievements/ milestones located within the course structure allow the domain expert to develop learning objects with clear goals?), which represents the contextualized and goal-oriented game mechanism, has a mean value $(\mu=2.58, \sigma=0.633)$ as the lowest value for the gamification evaluating category. This item is one of the game mechanics that is concerned with 
determining a clear target/goal for the exercise presented. Therefore, having it as the least agreed item indicates that the intersection between the course development and game mechanics is still unpracticed by some participants.

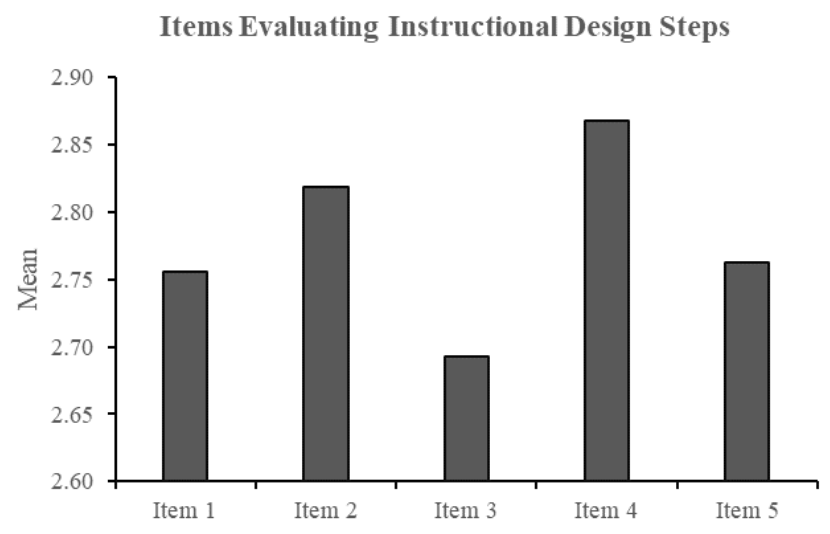

(a) The evaluation results of PAGE model from the instructional design steps perspective

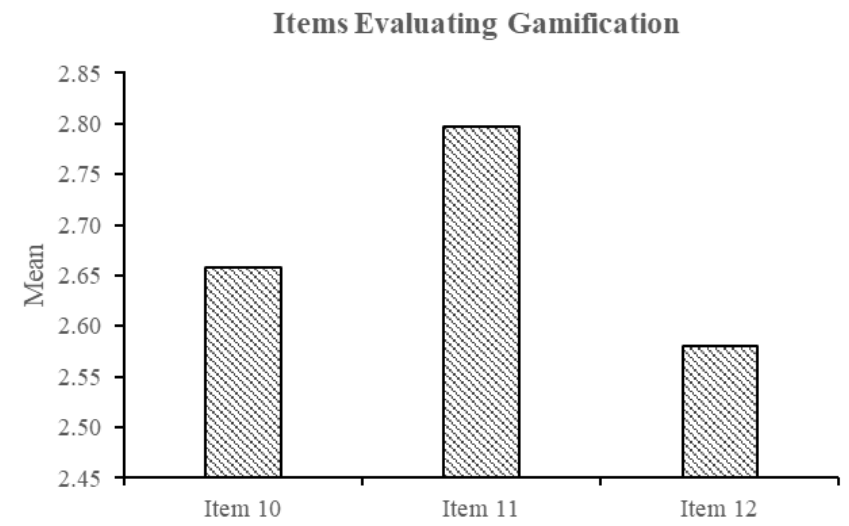

(c) The evaluation results of PAGE model from the gamification perspective

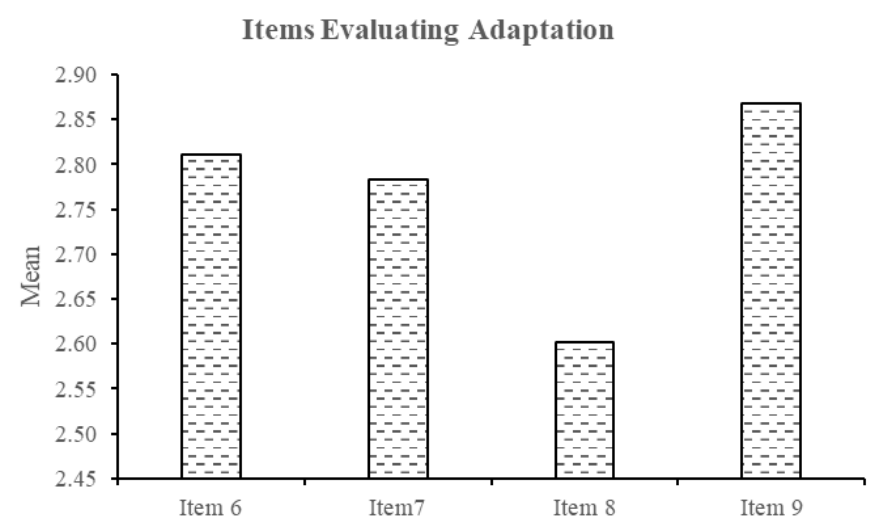

(b) The evaluation results of PAGE model from the adaptation perspective

Items Evaluating Learning Experience

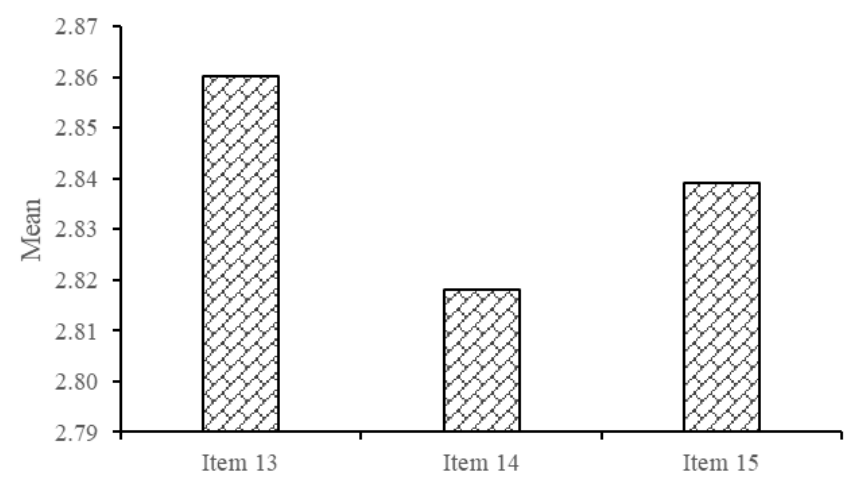

(d) The evaluation results of PAGE model from the learning experience perspective

Figure 3: The evaluation results of PAGE model from the evaluating categories perspective

The Learning Experience Evaluating Category: Regarding the PAGE model effect on the learning experience, three items have been examined, for which their results are reflected in Figure 3(d). Item 13 (Does the leader board in the model help boosting the learner's enthusiasm to keep motivated?) has the highest mean value $(\mu=2.86, \sigma=0.386)$ compared to the other items. This item got only 2 'Disagree' choice, assuring that the motivation factor was successfully applied in the proposed model, with a positive effect on the learner. Followed by item $15(\mu=2.84, \sigma=0.438)$, then Item 14 (Does the fictional story in the model help engaging the learners?) $(\mu=2.82, \sigma=0.438)$ came last, with 3 'Disagree' and 20 'I'm not sure' choices. The high number of uncertainties, compared to the low number of disagreements, implies that the 
fictional story, as a concept under game mechanics, is unfamiliar or unpracticed by some participants rather than disapproved in order to decide whether it is effective in the proposed model.

The Course Design Module: As shown in Figure 4(a), the Course Design Module has been evaluated through 11 items. Item 9 (Does presenting the course concepts as a set of learning objects allow them to be reused and modified independent of the course structure?) got the highest mean value ( $\mu=2.87, \sigma=0.415)$, which discusses the learning object concept as a part of the adaptation evaluating category, having item 12 with the least mean value $(\mu=2.58, \sigma=0.633)$. Moreover, in this module, the overall mean value per each evaluating category is as follows: $\mu=2.76, \mu=2.77, \mu=2.62$, and $\mu=2.82$ respectively. This indicates that this module positively impacts and enhances the learning experience, followed by adaptation, the instructional design steps, and lastly the gamification evaluating category as per the resultant average values. This is probably because blended learning and gamification are two unexplored concepts by some participants, causing lack of judgement.

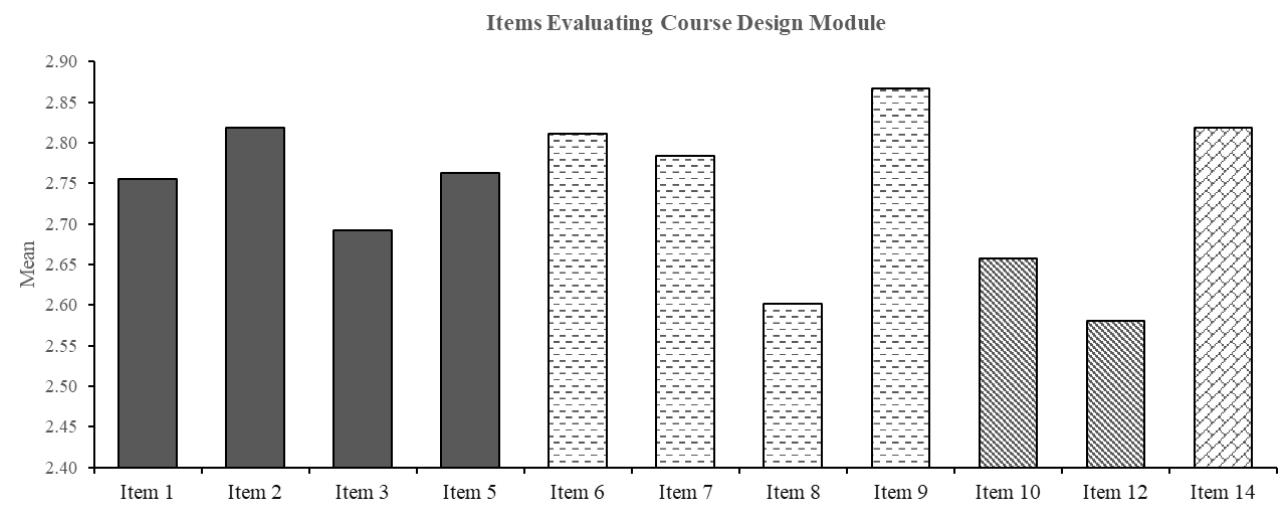

(a) The evaluation results of PAGE model from the course design module perspective

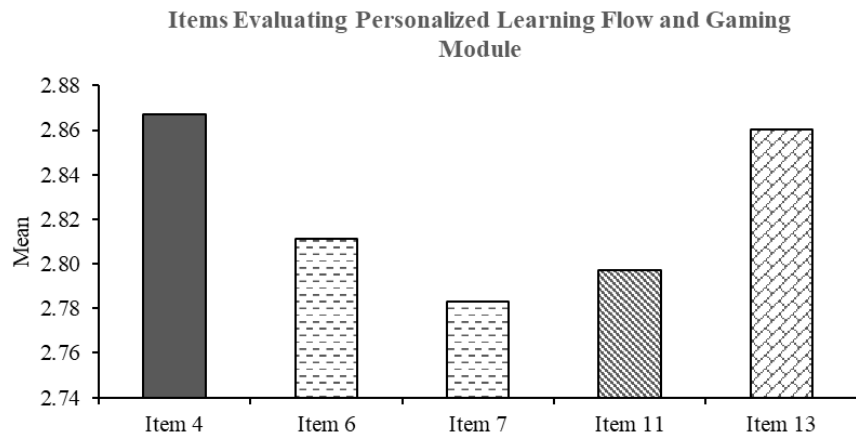

(b) The evaluation results of PAGE model from the Personalized Learning Flow and Gaming Module perspective

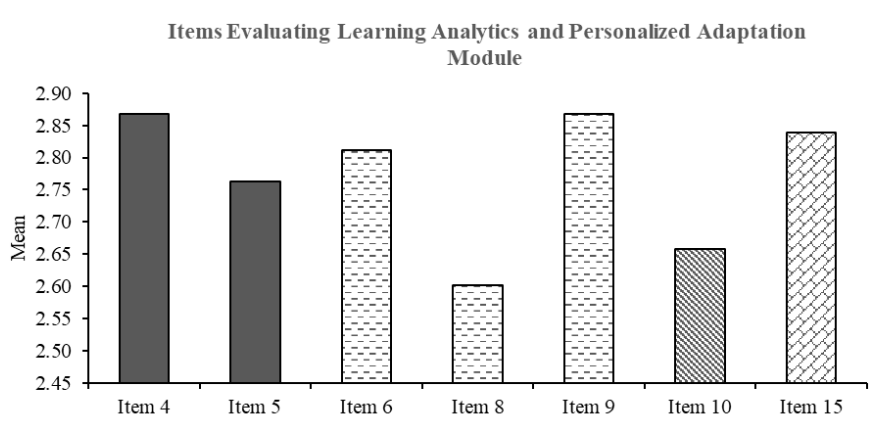

(c) The evaluation results of PAGE model from the Learning Analytics and Personalized Adaptation Module perspective

Figure 4: The evaluation results of PAGE model from the PAGE modules perspective The Personalized Learning Flow and Gaming Module: Figure 4(b) presents the 5 items evaluating the Personalized Learning Flow and Gaming module. Item 4 (Does the model analyze the learner's performance which in turn forms feedback on the learning object/course quality?) has been evaluated as the 
highest mean value $(\mu=2.87, \sigma=0.380)$, which discusses the tracking of the learning behavior as a part of the instructional design steps evaluating categories. Item 7 (Does the model allow for adapting the learner's knowledge and skill level efficiently?) is the one with the least mean value $(\mu=2.78, \sigma=0.462)$, with 'Disagree' of 3 and 25 and 'I'm not sure'. This is probably due to that some participants did not apply adaptation as per the content and its difficulty levels in the traditional educational process, which makes it difficult for them to judge. Yet, the average values for all items presented in Figure 4(b) concerning this module are: $\mu=2.87, \mu=2.80, \mu=2.80$, and $\mu=2.86$ for the four evaluating categories respectively. This deduces that the instructional design steps are accurately applied and positively influenced in this module, followed by the learning experience, then gamification and adaptation evaluating categories. 
The Learning Analytics and Personalized Adaptation Module: Figure 4(c) shows the 7 items evaluating the Learning Analytics and Personalized Adaptation Module. Item 9 (Does presenting the course concepts as a set of learning objects allow them to be reused and modified independent of the course structure?) got the most agreements with mean value $(\mu=2.87, \sigma=0.415)$, assuring that this module successfully supports the reusability of created LOs, facilitating the adaptation on them. Item 8 (Does the model allow for adapting the rewarding mechanism for a learning object?) has the least mean value $(\mu=2.60, \sigma=0.652)$, which is related to the evaluation adaptation as discussed and justified earlier in the previous sub-section. However, the average values for each evaluating category regarding this module are: $\mu=2.81, \mu=2.76, \mu=2.66$, and $\mu=2.84$ respectively. This highlights that the learning experience is best achieved in this module, followed by the instructional design steps, adaptation, making the gamification as the least adopted evaluating category.

\section{The Proposed Learning Preferences Adaptor}

The successful learning process means that the learner proceeds as expected, advancing in skills and/or knowledge level. One of the main factors that influence the success of a learning process is the learner portfolio's accuracy. The learner portfolio repository is the main gateway to understand the learner's characteristics and needs. Any flaw in this portfolio means that less accurate LOs will be selected and presented to the learner, leading to a negative learning progress.

The role of Learner Analyzer is to evaluate the learner's behavior in order to identify whether the learner preferences have accurately defined the learner's learning preferences, or a modification is needed. It starts by identifying the suitable cluster for learner $_{i}$ out of $k$ clusters according to the learners' similarities in the learning style $L S_{i}$ ) and the learning behavior $L B_{i j}$ clarified in (4) and (9) (Y.Maher, S.Moussa, \& E.Khalifa, 2020) for $L O_{j}$ of $\operatorname{course} e_{c}$. The clustering is based on the K-Means centroidbased clustering technique (Han, Kamber, \& Pei, 2012). All clusters are stored in the Course \& OERs Metadata repositories. The centroid is defined by the mean of learner $_{i}$ learning style, and the learning behavior. Figure 5 shows the learners in cluster $C S_{x} j$ regarding $O E R_{j}$.

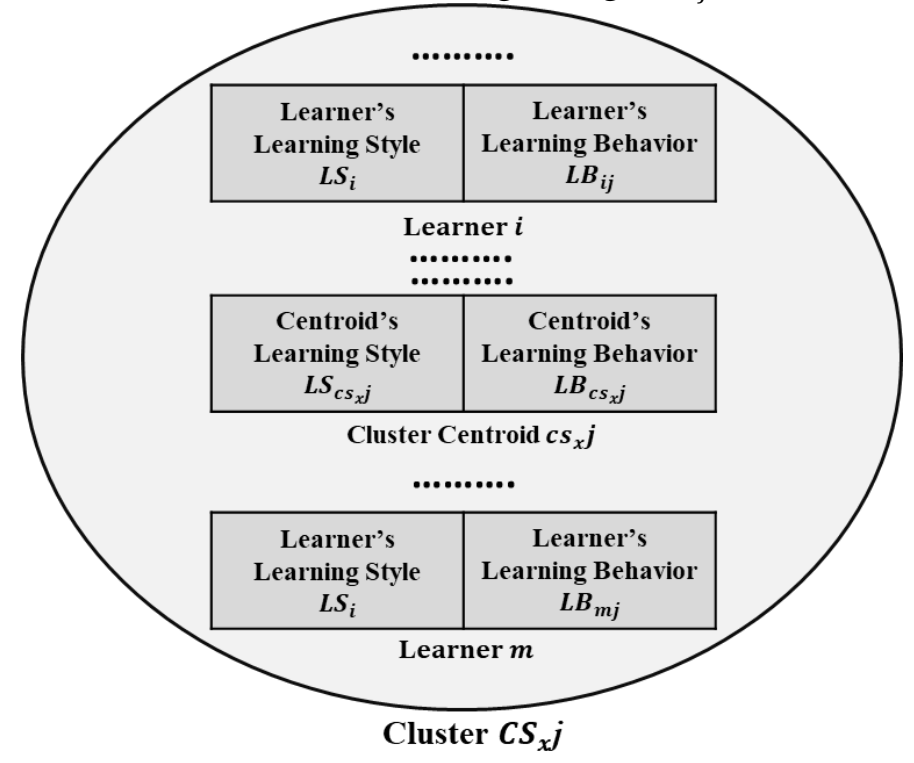

Figure 5: The learners in cluster $C S_{x} j$ regarding $O E R_{j}$

Let $c S_{x} j$ be the centroid for cluster $C S_{x} j$ regarding $O E R_{j}$, having learning style $L S_{c s_{x}}$ and learning behavior $L B_{c s_{x} j}$ as shown in (1):

$$
C S_{x} j=<\frac{\sum_{i=1}^{m}\left(L S_{i}\right)}{m}, \frac{\sum_{i=1}^{m}\left(L B_{i j}\right)}{m}>
$$


Where $m$ is the total number of learners in cluster $C S_{x} j$ and $1 \leq i \leq m, k$ is the number of clusters, and $1 \leq x \leq k, L S_{i}$ is the learning style for learner $_{i}$, whereas $L B_{i j}$ is the learning behavior of learner $_{i}$ regarding $O E R_{j}$ respectively. Figure 5 shows a sample of cluster $C S_{x} j$ for $m$ learners regarding $O E R_{j}$, in which each learner $_{i}$ is clustered by his/her learning style $L S_{i}$ and learning behavior $L B_{i j}$. Let dist_LS $\left(\right.$ learner $_{i}, C s_{x} j$ ) be the distance measured between $l e a r n e r_{i}$ and centroid $c S_{x} j$ of cluster $C S_{x} j$ regarding $\mathrm{LO}_{\mathrm{j}}$ as shown in (2), based on the learning style $L S_{i}$ clarified in (Y.Maher, S.Moussa, \& E.Khalifa, 2020):

$$
=\sqrt{\left(P 1_{i}-P 1_{c s_{x} j}\right)^{2}+\left(P 2_{i}-P 2_{c s_{x} j}\right)^{2}+\left(P 3_{i}-P 3_{c s_{x} j}\right)^{2}+\left(P 4_{i}-P 4_{c s_{x} j}\right)^{2}}
$$

Where $P 1_{i}, P 2_{i}, P 3_{i}$, and $P 4_{i}$ are the pole values of the learning style's four dimensions for learner $_{i}$, and $P 1_{c s_{x} j}, P 2_{c s_{x} j}, P 3_{c s_{x} j}$, and $P 4_{c s_{x} j}$ are the pole values of the learning style's four dimensions for centroid $c S_{x} j$ of cluster $C S_{x} j$ regarding $\mathrm{LO}_{\mathrm{j}}$. Similarly, let dist $_{L B\left(\text { learner }_{i}, c s_{x} j\right)}$ be the distance measured between learner $r_{i}$ and centroid $c s_{x} j$ of cluster $C S_{x} j$ regarding the tracked behavior of learner $_{i}$ in $L O_{j}$ as shown in (3), based on the learning behavior $L B_{i j}$ clarified in (Y.Maher, S.Moussa, \& E.Khalifa, 2020):

$$
\operatorname{dist}_{-} L B\left(\text { learner }_{i}, C s_{x} j\right)=\sqrt{\left(F A_{i j}-F A_{c s_{x} j}\right)^{2}+\left(T T_{i j}-T T_{c s_{x} j}\right)^{2}+\left(W A_{i j}-W A_{c s_{x} j}\right)^{2}}
$$

Where $F A_{i j}$ and $F A_{c s_{x} j}$ are the failed attempts, $T T_{i j}$ and $T T_{c s_{x} j}$ are the total time taken, and $W A_{i j}$ and $W A_{c s_{x} j}$ are the total number of wrong actions for learner $_{i}$ and centroid $c s_{x} j$ of cluster $C S_{x} j$ regarding $L O_{j}$ respectively.

These similarity evaluations between learner $_{i}$ and the centroids of the $k$ clusters for $L O_{j}$ eventually result in one of the following three cases:

- Case 1: Both dist_LS and dist_LB of learner regarding $L O_{j}$ are close to the same cluster.

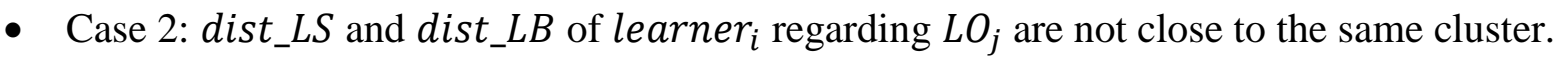

- Case 3: dist_LS of learner ${ }_{i}$ is not close enough to any cluster.

According to the resulted case, a modification indicator $\boldsymbol{M} \boldsymbol{I}_{-} \boldsymbol{L} \boldsymbol{S}_{\boldsymbol{i}}$ is assessed to identify whether a modification is required to the learning style of learner $_{\boldsymbol{i}}$ 's portfolio, presented by true or false. Algorithm 1 represents how learner $_{\boldsymbol{i}}$ is clustered as per the different similarity evaluation cases and the resultant modification indicator $M I_{-} L S_{i}$. If both $\boldsymbol{d i s t}_{-} \boldsymbol{L S}$ and $\boldsymbol{d i s t}_{-} \boldsymbol{L B}$ of learner $_{\boldsymbol{i}}$ regarding $\boldsymbol{L} \boldsymbol{O}_{j}$ are closer to the same cluster, this means that learner $_{\boldsymbol{i}}$ has behaved in a way similar to that of similar previous learners regarding $\boldsymbol{L O}_{\boldsymbol{j}}$. Accordingly, learner $_{\boldsymbol{i}}$ is added to their cluster, where no modification to the learning style of $\boldsymbol{l e a r n e r}_{\boldsymbol{i}}$ is needed, represented as $\boldsymbol{M} \boldsymbol{I}_{-} \boldsymbol{L} \boldsymbol{S}_{\boldsymbol{i}}=$ false. Case 2 reveals that $\boldsymbol{l e a r n e r}_{\boldsymbol{i}}$ has behaved in a way similar to a different cluster than that representing learner $_{\boldsymbol{i}}$ 's learning style. Eventually, learner $_{\boldsymbol{i}}$ should reside in one cluster, either in the cluster representing his/her learning style, or that representing his/her learning behavior regarding $\boldsymbol{L} \boldsymbol{O}_{\boldsymbol{j}}$. This decision is made by calculating

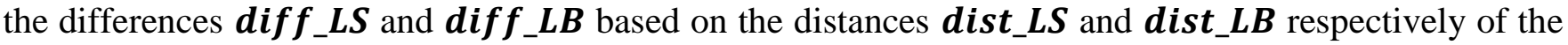
candidate clusters and learner $_{\boldsymbol{i}}$. This identifies whether it is closer to locate learner $_{\boldsymbol{i}}$ in the cluster of similar learning behavior, or of similar learning style. Table 2 summarizes the scenarios for the resulted $\operatorname{diff}_{-} L S$ and $\operatorname{diff}_{-} L B$. 
Algorithm 1

Clustering learner ${ }_{i}$ according to dist_LS and dist_LB.

1. Initialize diff_LS $=0$, diff_LB $=0, \operatorname{stdDevLS}=0$, stdDevLB=0

2. Initialize $\boldsymbol{M} I_{-} L \boldsymbol{S}_{\boldsymbol{i}}=$ false

3. Initialize $L S_{-}$Threshold $=1, L B_{-}$Threshold $=\sqrt[2]{3} / 2$

\section{Initialize cluster $O \boldsymbol{f} \boldsymbol{L} \boldsymbol{S}=\left(\right.$ null, $\boldsymbol{L} \boldsymbol{S} \_$Threshold $\left.* 2\right)$}

5. Initialize clusterOf $L B=\left(\right.$ null, $L B_{-}$Threshold $\left.* 2\right)$

6. for $x=1$ to $k$ do

7. for $\boldsymbol{i}=\mathbf{1}$ to $\boldsymbol{m}$ do

8. if dist $_{-} L S\left(L S_{i}, L S_{c s_{x} j}\right)<$ value of clusterOf $L S$ then

9. Set clusterOf $L S=\left(C S_{x}, \operatorname{dist}_{-} L S\left(L S_{i}, L S_{c s_{x} j}\right)\right)$

10. if dist_LB $\left._{-} L \boldsymbol{L B}_{i}, L B C s_{x} j\right)<$ value of clusterOf $L B$ then

11. Set clusterOfLB $=\left(C S_{x}\right.$, dist $\left._{-} L B\left(L B_{i}, L B C s_{x} j\right)\right)$

12. $\quad$ Normalize values of $\boldsymbol{L} \boldsymbol{B}_{\boldsymbol{i j}}$ and $\boldsymbol{L} \boldsymbol{B}_{\boldsymbol{c s}} \boldsymbol{j}$

13. end for

14. end for

15. if value of clusterOf $L S<=L S_{-}$Threshold AND value of clusterOf $L B<=L B_{-}$Threshold then \{

16. if key of clusterOfLS = key of clusterOfLB then

17.

18. $\quad \boldsymbol{M} \boldsymbol{I}_{-} \boldsymbol{L} \boldsymbol{S}_{\boldsymbol{i}}=$ false

19. add learner $_{i}$ to cluster key of clusterOfLS

20. $\}$

21. else if key of clusterOfLS $!=$ key of clusterOfLB then

22. \{

23.

$$
\operatorname{diffLS}=\mid \operatorname{dist}_{-} L S\left(L S_{i}, L S_{c s_{\text {key of clusterofLS }}}\right)
$$

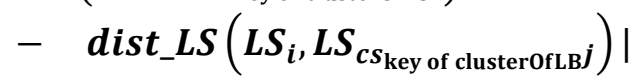

24. $\quad \operatorname{diff} L B=\mid$ dist_L $_{-} L B\left(L B_{i}, L B_{c s_{\text {key of clusterof } L S j}}\right)$

$$
\text { - } \operatorname{dist}_{-} L B\left(L B_{i}, L B_{\left.c s_{\text {key of clusterOfLB }} j\right) \mid}\right.
$$

25. if $\operatorname{diff} L S \leq \operatorname{diff} L B$ then \{

26. add learner $_{i}$ to cluster key of clusterOfLS

27. $\boldsymbol{M} I_{-} \boldsymbol{L} \boldsymbol{S}_{\boldsymbol{i}}=$ false $\}$

28. else \{

29. add learner $_{\boldsymbol{i}}$ to cluster key of clusterOfLB

30. $\quad \boldsymbol{M} \boldsymbol{I}_{-} \boldsymbol{L} \boldsymbol{S}_{\boldsymbol{i}}=$ true

31. Adapt learner ${ }_{i}$ 's portfolio \}

32. end if \}

33. else \{
// a key-value pair indicating the cluster identity as the key and the value representing the minimum distance between the current learner' learning style and the nearest cluster

// a key-value pair indicating the cluster identity as the key and the value representing the minimum distance between the current learner' learning behavior and the nearest cluster

//loop for all clusters

//loop for all learners inside the current cluster $\mathrm{x}$

// update with the cluster identity having the shortest distance for the learning style similarity

// update with the cluster identity having the shortest distance for the learning behavior similarity

// similarity will be accepted if it is below or equal to the threshold

//case 1

// no need to modify the current learner's LS

//case 2

// Scenario 1 and 2

// the current learner's LS does not need modification

// Scenario 3

// modification required to the current learner's LS

//case 3 


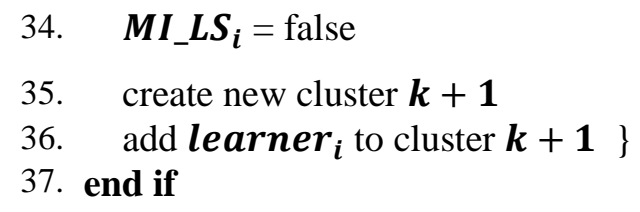

// no need to modify the current learner's LS

If diff_LS is equal to or smaller than diff_LB as in scenario 1 and 2 respectively, then the priority is to add learner ${ }_{i}$ to the cluster representing his/her learning style in order to avoid unnecessary modification for the learning style. In scenario 3, learner ${ }_{i}$ will be clustered into the cluster representing his/her learning behavior, indicating that the learning style associated with learner $r_{i}$ does not accurately define that learner. This inaccurate association of learning style resulted that learner $\mathrm{r}_{\mathrm{i}}$ was presented with a $\mathrm{LO}_{\mathrm{j}}$ of a wrong learning style $\mathrm{LS}_{\mathrm{j}}$, in which her/his learning behavior was not the best performance. Accordingly, learner ${ }_{i}$ 's learning style will be modified to fit with the learning style of the designated cluster. When a modification to learner ${ }_{i}$ 's learning style is required (MI_LS $S_{i}=$ true), then both the learning styles of learner ${ }_{i}$ and the centroid of the cluster - to which learner ${ }_{i}$ will reside - are transferred to the Learning Recommendation and Adaptation sub-module.

Table 2. The clustering decision for the different resulted comparison scenarios

\begin{tabular}{|c|c|c|c|}
\hline Scenario & $\operatorname{diff}_{-} L S$ & $\operatorname{diff}_{-} L B$ & Clustering Decision \\
\hline 1 & Equal & Equal & \multirow{2}{*}{$\begin{array}{l}\text { learner }_{i} \text { is clustered into the cluster representing his/her learning } \\
\text { style }\end{array}$} \\
\hline 2 & Smaller & Greater & \\
\hline 3 & Greater & Smaller & $\begin{array}{c}\text { learner }_{i} \text { is clustered into the cluster representing his/her learning } \\
\text { behavior }\end{array}$ \\
\hline
\end{tabular}

On the other hand, case 3 implies that learner $_{i}$ has a different learning style than that of all other enrolled learners. Accordingly, a new cluster is created for learner $_{i}$, having $M I_{-} L S_{i}=$ false. The case that dist_LB of learner ${ }_{i}$ is not close enough to any cluster is negligible, as it does not affect the action performed, since the resultant modification indicator mainly depends on the dist_LS that is handled in all cases. However, regardless of the three cases, the learner will not be assigned to any cluster unless both dist_LS $_{-}$and dist_LB satisfy their thresholds, as shown in line 16 of Algorithm 1.

The clustering threshold for learning style Threshold_LS is derived by substituting in the distance equation in (2) to calculate the maximum distance of learning style $M X_{-}$dist $_{-} L S$ as shown in (4), assuming one party has the extreme learning style values of $(1,1,1,1)$, and the other has the least learning style values of $(0,0,0,0)$, whereas the minimum distance of learning style $M N_{-} d i s t L L S$ is calculated by assuming that both parties have learning style values of $(1,1,1,1)$ as shown in (5). Accordingly, the clustering threshold Threshold_LS is computed as the average value of (4) and (5), presented in (6):

$$
\begin{gathered}
M X_{-} d i s t_{-} L S=\sqrt[2]{(1-0)^{2}+(1-0)^{2}+(1-0)^{2}+(1-0)^{2}}=2 \\
M N_{-} d i s t_{-} L S=\sqrt[2]{(1-1)^{2}+(1-1)^{2}+(1-1)^{2}+(1-1)^{2}}=0 \\
\text { Threshold_LS }=\frac{M X_{-} \text {dist_L }_{-} L S+M N_{-}{ }_{\text {dist }} L S}{2}=1
\end{gathered}
$$

Where $M X_{-}$dist_LS and $M N_{-}$dist_L $_{-} L S$ are the maximum and minimum calculated distance of learning style between two parties respectively. Therefore, dist_LS must not exceed the threshold value 
Threshold_ $L S=1$ as presented in (6), the learning style strictly ranges from 0 to 1 . Unlike dist $_{-} L B$ that has dynamic extremes, since the minimum and maximum learning behavior values $M N_{-} L B$ and $M X_{-} L B$ are pre-defined by the domain expert as discussed in (Y.Maher, S.Moussa, \& E.Khalifa, 2020), which may vary as per $L O_{j}$. Thus, the learning behavior $L B_{i j}$ of learner ${ }_{i}$ for $L O_{j}$ presented in (Y.Maher, S.Moussa, \& E.Khalifa, 2020) should be normalized to range between 0 and 1 by applying the min-max normalization technique (Han et al., 2012). Let $M X_{-}$dist_LB $_{-} B$ and $M N_{-}$dist_L $_{-} B$ be the maximum and minimum distance values for learning behavior as shown in (7) and (8) respectively. Let Threshold_LB be the clustering threshold for learning behavior as shown in (9):

$$
\begin{gathered}
M X_{-} \text {dist_LB }=\sqrt[2]{(1-0)^{2}+(1-0)^{2}+(1-0)^{2}}=\sqrt[2]{3} \\
M N_{-} d i s t_{-} L B=\sqrt[2]{(1-1)^{2}+(1-1)^{2}+(1-1)^{2}}=0 \\
T h r e s h o l d \_L B=\frac{M X_{-} d i s t_{-} L B+M N_{-} d i s t_{-} L B}{2}=\frac{\sqrt[2]{3}}{2}
\end{gathered}
$$

Where $M X_{-} d i s t_{-} L B$ and $M N_{-} d_{i s t} L B$ are the maximum and minimum calculated distance of learning behavior between two parties respectively. Therefore, dist_LB must not exceed the threshold value Threshold_LB $=\frac{\sqrt[2]{3}}{2}$ as presented in (9).

Example 1: Assume that there are two learners (Noah and Nancy) and three clusters (1, 2 and 3) for $L O_{21}$ named "Addition of two numbers". The results after accomplishing $L O_{21}$ are as follows:

- Learner name: Noah and ID: 1104 , has $L S_{1104}=(0.7,0.6,0.3,0.5)$ and $L B_{110421}=(4,16,21)$.

- Learner name: Nancy and ID: 2209 , has $L S_{2209}=(0.2,0.1,0.7,0.6)$ and $L B_{2209} 21=(3,9,20)$.

- Cluster $C S_{1} 21$ has centroid $c s_{1} 21$ with $L S_{c s_{1} 21}=(0.4,0.1,0.8,0.5)$ and $L B_{c s_{1} 21}=(5,10,25)$.

- Cluster $C S_{2} 21$ has centroid $c s_{2} 21$ with $L S_{C S_{2} 21}=(0.6,0.7,0.2,0.4)$ and $L B_{c S_{2} 21}=(3,15,18)$.

- Cluster $C S_{3} 21$ has centroid $c s_{3} 21$ with $L S_{C S_{3} 21}=(0.6,0.9,0.1,0.3)$ and $L B_{C s_{3} 21}=(4,13,22)$.

- For $L O_{21}$, the pre-defined $M N_{-} L B_{21}$ is $(0,6,0)$, while $M X_{-} L B_{21}$ is $(10,20,30)$.

The distance-based approach is applied as shown in Algorithm 1 to cluster these learners. As a preprocessing step, the learning behaviors are normalized using the min-max normalization technique for all clusters and learners, where the results are as follows:

- $L B_{1104}{ }^{\prime}=(0.4,0.714,0.7)$.

- $L B_{2209}{ }^{\prime}=(0.3,0.214,0.667)$.

- $L B_{C S_{1} 21^{\prime}}=(0.5,0.286,0.833)$.

- $L B_{C s_{2} 21}^{\prime}=(0.3,0.642,0.6)$.

- $L B_{C S_{3} 21^{\prime}}=(0.3,0.286,0.667)$.

- For $L O_{21}$, the pre-defined $M N_{-} L B_{21}{ }^{\prime}$ is $(0,0,0)$, while $M X_{-} L B_{21}{ }^{\prime}$ is $(1,1,1)$.

As for Noah, his $L B_{110421}$ and $L S_{1104}$ are compared with those of the two clusters to find the least dist_LS and dist_LB presented in (2) and (3) as follows:

- Cluster 1: dist_LS $\left(\right.$ learner $\left._{1104}, C s_{1} 21\right)=0.768$, dist_LB $\left(\right.$ learner $\left._{1104}, C s_{1} 21\right)=0.46$.

- Cluster 2: dist_LS(learner $\left.{ }_{1104}, C S_{2} 21\right)=0.2$, dist_LB $\left(\right.$ learner $\left._{1104}, C S_{2} 21\right)=0.158$.

- Cluster 3: dist_LS $\left(\right.$ learner $\left._{1104}, c s_{3} 21\right)=0.424$, dist_LB $\left(\right.$ Learner $\left._{1104}, c s_{3} 21\right)=0.441$.

Observing the results, the least dist_LS is 0.2 for cluster $C S_{2} 21$, setting clusterOfLS $=(2,0.2)$. The least dist_LB for $L O_{21}$ is 0.158 for cluster $C S_{2} 21$, setting clusterOfLB $=(2,0.158)$. Accordingly, the values of dist_LS and dist_LB residing in clusterOfLS and clusterOfLB are checked against their thresholds as 
specified in (6) and (9) respectively. After confirming the validity of $d_{i s t_{-}} L S$ and $d i s t_{-} L B$ for Noah, the least distances for dist_LS and dist_LB are of the same cluster. Thus, Noah satisfies case 1 , to be clustered into cluster $C S_{2} 21$, where $M I_{-} L S_{1104}=$ false to indicate that no change in his learning style is required.

Regarding Nancy, her $L B_{2209} 21$ and $L S_{2209}$ are compared in a similar manner, where results are as follows:

- Cluster 1: dist_LS $\left(\right.$ learner $\left._{2209}, C S_{1} 21\right)=0.245$, dist_LB $\left(\right.$ learner $\left._{2209}, C S_{1} 21\right)=0.27$.

- Cluster 2: dist_LS $\left(\right.$ learner $\left._{2209}, C S_{2} 21\right)=0.9$, dist_LB $\left(\right.$ learner $\left._{2209}, C S_{2} 21\right)=0.434$.

- Cluster 3: dist_LS $\left(\right.$ learner $\left._{2209}, C S_{3} 21\right)=1.118$, dist_LB $\left(\right.$ Learner $\left._{2209}, C S_{3} 21\right)=0.071$.

Observing the results, the least dist_LS is 0.245 for cluster $C S_{1} 21$, setting clusterOfLS $=(1,0.245)$. The least dist_LB for $L O_{21}$ is 0.071 for cluster $C S_{3} 21$, setting clusterOfLB $=(3,0.071)$. Accordingly, the values of dist_LS and dist_LB residing in clusterOfLS and clusterOfLB are checked against their thresholds as specified in (6) and (9) respectively. After confirming the validity of dist_LS and dist_LB for Nancy, the least distances for both $\operatorname{dist}_{-} L S$ and dist_LB are of dissimilar clusters, which satisfies case 2 . In this case, diffLS and diffLB are calculated by subtracting dist_LS and dist_LB of clusters $C S_{1}$ and $C S_{3}$ respectively. As a result, diffLS $=0.873$ and diffLB $=0.199$, revealing that diffLB is smaller than diffLS to indicate that it is convenient to reside Nancy in cluster $C S_{1}$, having $M I_{-} L S_{2209}=$ false, where no change in her learning style is required.

Example II: Assume that there is another learner Sarah and two clusters (1 and 2). The results after accomplishing $\mathrm{LO}_{21}$ "Addition of two numbers" are as follows:

- Learner name: Sarah and ID: 0408, has $L S_{0408}=(0.2,0.8,0.1,0.2)$ and $L B_{040821}=(1,7,3)$.

- Cluster $C S_{1}$ has centroid $c s_{1}$ with $L S_{c s_{1} 21}=(0.8,0.2,0.9,1)$ and $L B_{c s_{1} 21}=(9,18,28)$.

- Cluster $C S_{2}$ has centroid $c S_{2}$ with $L S_{C s_{2} 21}=(0.7,0.1,1,0.9)$ and $L B_{c s_{2} 21}=(8,19,27)$.

- For $L O_{21}$, the pre-defined $M N_{-} L B_{21}$ is $(0,6,0)$, while $M X_{-} L B_{21}$ is $(10,20,30)$.

The distance-based approach is applied to cluster this learner. As a pre-processing step, the learning behavior is normalized using the min-max normalization technique for all clusters. The new maximum and minimum are 1 and 0 respectively, resulting as follows:

- $L B_{040821}{ }^{\prime}=(0.1,0.071,0.1)$.

- $L B_{C s_{1} 21^{\prime}}=(0.9,0.858,0.933)$.

- $L B_{C s_{2} 21}{ }^{\prime}=(0.8,0.929,0.9)$.

- For $L O_{21}$, the pre-defined $M N_{-} L B_{21}{ }^{\prime}$ is $(0,0,0)$, while $M X_{-} L B_{21}{ }^{\prime}$ is $(1,1,1)$.

Sarah's $L S_{0408}$ and $L B_{040821}$ are compared to those of the two clusters to find the least dist_LS and dist_LB presented in (2) and (3) as follows:

- Cluster 1: dist_LS $\left(\right.$ learner $\left._{0408}, c s_{1} 21\right)=1.414$, dist_LB $\left(\right.$ learner $\left._{0408}, c s_{1} 21\right)=1.397$.

- Cluster 2: dist_LS $\left(\right.$ learner $\left._{0408}, C s_{2} 21\right)=1.428$, dist_LB $\left(\right.$ learner $\left._{0408}, C s_{2} 21\right)=1.366$.

Observing her results, the least dist_LS is 1.414 of cluster $C S_{1}$, setting clusterOfLS $=(1,1.414)$. The least dist_LB is 1.366 of cluster $C S_{2}$, setting clusterOfLB $=(2,1.366)$. Accordingly, the values of dist_LS and dist_LB residing in clusterOfLS and clusterOfLB are checked against their thresholds as specified in (9) and (9) respectively. After checking the validity of dist_LS and dist_LB for Sarah, the least distances for both dist_LS $_{-}$and dist_LB have crossed the threshold boundaries, i.e.; satisfying case 3. Therefore, Sarah is clustered into in a newly created cluster $C S_{3}$, having $M I_{-} L S_{0408}=$ false to indicate that no change in her learning style is required. 
On the other hand, the domain expert may have accurately described the objectives of the LO, but failed to develop it as required, i.e. unclear goals that make the learner lost in the process, or a poor rewarding mechanism that discourages the learner to learn eagerly, etc. Therefore, the Learning Behavior \& Feedback Monitor collects feedback about the developed LO to determine if it has a problem. The exact problem should be precisely determined to recommend to the domain expert the required modification(s). Thus, the Course and LO Analyzer evaluates the LO using two main factors as presented earlier in Table 2: (i) the current learner ${ }_{i}$ 's feedback $F B_{i j}$ and $F B_{i c}$ stored in the Learning Behavior and Feedback repository, and (ii) the accumulated feedbacks $F B_{j}$ and $F B_{c}$ for each accomplished LO and its course respectively, which are stored in the Course and LOs Metadata

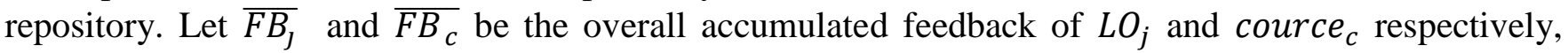
associated with their metadata in the Course and LOs Metadata repository. $F B_{j}$ represents the LO rating score, whereas $F B_{c}$ represents the course rating score as shown below in (10) and (11):

$$
\begin{gathered}
F B_{j}=\left\langle\overline{R M_{\jmath}}, \overline{D L_{\jmath}}, \overline{G C_{J}}, \overline{A C_{J}}>\right. \\
F B_{C}=<\overline{F S_{c}}>
\end{gathered}
$$

Where $\overline{R M_{J}}, \overline{D L_{\jmath}}, \overline{G C_{J}}, \overline{A C_{J}}$ are the mean values of feedback for all enrolled learners who have accomplished $L O_{j}$ for the rewarding mechanism, difficulty level, goal clarity, and assets combination of $L O_{j}$ respectively. $\overline{F S_{c}}$ is the mean value of feedback for all learners enrolled in cource $_{c}$ concerning its fictional story and have accomplished $L O_{j}$. Since the feedback values ranging from 0 to 2 indicate a positive feedback, while value 3 indicates a negative feedback, accordingly, if the mean value for any principle is between 0 and 2, then this principle will not encounter any modification, having its modification indicator $M I_{-} L O_{j}=$ false, while any score between 2.1 and 3 will set $M I_{-} L O_{j}=$ true, in which $L O_{j}$ is triggered in the Learning Recommendation and Adaptation sub-module to modify the negatively-feedbacked principles. However, the feedbacks $F B_{i j}$ and $F B_{i c}$ of the current learner $_{i}$ concerning $L O_{j}$ and cource $_{c}$ will not be considered into the accumulated feedbacks $F B_{j}$ of $L O_{j}$ and $F B_{c}$ of cource $_{c}$ unless the modification indicator of learning style for learner ${ }_{i} M I_{-} L S_{i}$ is checked. If $M I_{-} L S_{i}$ is false, this means that the learner $_{i}{ }^{\prime} s$ learning style needs no modification and that the represented $L O_{j}$ is a correct match. Thus, $F B_{i j}$ and $F B_{i c}$ will be accumulated into $F B_{j}$ and $F B_{c}$ respectively. Otherwise, if $M I_{-} L S_{i}$ is true, this means that the learner $_{i}{ }^{\prime} s$ learning style did not correctly define that learner, which led to an incorrect selection for $L O_{j}$. Thus, the feedback of learner $r_{i}$ will be ignored.

\section{Conclusion and Future Work}

In this paper, a learning preferences adaptation model is proposed based on the Personalized Adaptive Gamified E-learning (PAGE) model to enrich learning analytics. The PAGE model's survey was discussed in detail, creating a platform that combines generic course design facilities along with the adaptation, gamification, and personalized learning experience. The discussed survey results show that adaptation was a promising concept related to learning process success, urging to propose a learning preference adaptation. The proposed learning preferences adaptation model applied k-means clustering to help adapt the learner's learning preferences based on the similarity of tracked behaviour and preferences between learners. This proposed model satisfies the research gap question, in terms of merging the learning style-based adaptation and gamification concepts into a domain-independent elearning system that follows the instructional design steps of traditional classroom education, as well as supporting the supervision of parent/direct instructor as in blended learning, while allowing precise learning analytics. As for the future work, the potential for further analytics can be extended based on the PAGE model. This includes content adaptation and OER selection adaptation. Another direction would be the adaptation for the gamification aspect, where the game elements may be adapted according to learner's preferences with respect to the nature of the course. Moreover, collaborative learning may be investegated to be integrated with the PAGE model. 


\section{References}

Akbulut, Y., \& Cardak, C. S. (2012). Adaptive educational hypermedia accommodating learning styles: A content analysis of publications from 2000 to 2011. Computers and Education, 58(2), 835-842. https://doi.org/10.1016/j.compedu.2011.10.008

Almohammadi, k., hagras, h., alghazzawi, d., \& aldabbagh, g. (2017). A survey of artificial intelligence techniques employed for adaptive educational systems within e-learning, 7(1), 47-64.

Amin, A. E. (2019). An Intelligent Synchronous E-Learning Management System Based on MultiAgents of Linked Data, Ontology, and Semantic Service. International Journal of Intelligent Computing and Information Sciences, 19(1), 25-37.

Amin, A. E. (2019). Building Intelligent Semantic Educational System (ISES) Based on Ontology and Semantic Web Mining. International Journal of Intelligent Computing and Information Sciences, 19(1), 38-49.

Anouar Tadlaoui, M., Aammou, S., Khaldi, M., \& Novaes Carvalho, R. (2016). Learner Modeling in Adaptive Educational Systems: A Comparative Study. International Journal of Modern Education and Computer Science, 8(3), 1-10. https://doi.org/10.5815/ijmecs.2016.03.01

Asarta, C. J., \& Schmidt, J. R. (2017). Comparing student performance in blended and traditional courses: Does prior academic achievement matter? Internet and Higher Education, 32, 29-38. https://doi.org/10.1016/j.iheduc.2016.08.002

Boelens, R., Voet, M., \& Wever, B. De. (2018). SC. Computers \& Education. https://doi.org/10.1016/j.compedu.2018.02.009

Chen, X., Breslow, L., \& Deboer, J. (2018). Computers \& Education Analyzing productive learning behaviors for students using immediate corrective feedback in a blended learning environment. Computers \& Education, 117(September 2017), 59-74. https://doi.org/10.1016/j.compedu.2017.09.013

Clark-gordon, C. V, David, N., Hadden, A. A., \& Frisby, B. N. (2019). Computers \& Education College instructors and the digital red pen: An exploratory study of factors influencing the adoption and nonadoption of digital written feedback technologies. Computers \& Education, 128(October 2018), 414426. https://doi.org/10.1016/j.compedu.2018.10.002

Daradoumis, T., Manuel, J., Puig, M., Arguedas, M., \& Calvet, L. (2019). Computers \& Education Analyzing students ' perceptions to improve the design of an automated assessment tool in online distributed programming. Computers \& Education, 128(May 2018), 159-170. https://doi.org/10.1016/j.compedu.2018.09.021

Dominic, M., Britto, A. X., \& Francis, S. (2015). A Framework to Formulate Adaptivity for Adaptive eLearning System Using User Response Theory. International Journal of Modern Education and Computer Science, 7(1), 23-30. https://doi.org/http://dx.doi.org/10.5815/ijmecs.2015.01.04

Elabnody, M., Fouad, M., Maghraby, F., \& Hegazy, A. (2017). Framework for gamification based Elearning systems for higher education in Egypt. International Journal of Intelligent Computing and Information Sciences, 17(3), 85-97.

Erhel, S., \& Jamet, E. (2013). Computers \& Education Digital game-based learning: Impact of instructions and feedback on motivation and learning effectiveness. Computers \& Education, 67, 156167. https://doi.org/10.1016/j.compedu.2013.02.019

Erkens, M., \& Bodemer, D. (2019). Computers \& Education Improving collaborative learning : Guiding knowledge exchange through the provision of information about learning partners and learning contents. Computers \& Education, 128(October 2018), 452-472. https://doi.org/10.1016/j.compedu.2018.10.009

Huizenga, J., Admiraal, W., Akkerman, S., \& Ten Dam, G. (2009). Mobile game-based learning in secondary education: engagement, motivation and learning in a mobile city game: Original article. 
Journal of Computer Assisted Learning, 25(4), 332-344. https://doi.org/10.1111/j.13652729.2009.00316.x

Hussain, S. Y. S., Tan, W. H., \& Idris, M. Z. (2014). Digital Game-Based Learning For Remedial Mathematics Students: A New Teaching And Learning Approach In Malaysia. International Journal of Multimedia and Ubiquitous Engineering (IJMUE), 9(11), 325-338. https://doi.org/10.3850/978-981-090463-0

Hwang, G.-J., Sung, H.-Y., Hung, C.-M., Huang, I., \& Tsai, C.-C. (2012). Development of a personalized educational computer game based on students' learning styles. Educational Technology Research and Development, 60(4), 623-638. https://doi.org/10.1007/s11423-012-9241-x

Hwang, G. J., Wu, P. H., \& Chen, C. C. (2012). An online game approach for improving students' learning performance in web-based problem-solving activities. Computers and Education, 59(4), 12461256. https://doi.org/10.1016/j.compedu.2012.05.009

Jumaa, Y. M., Moussa, S. M., \& Khalifa, M. E. (2017). The Main Aspects of Adaptive Educational Games for Normal and Disabled / Disordered Learners : A Comprehensive Study, (ICICIS), 348-355.

Jung, E., Kim, D., Yoon, M., Park, S., \& Oakley, B. (2019). Computers \& Education The influence of instructional design on learner control, sense of achievement, and perceived effectiveness in a supersize MOOC course. Computers \& Education, 128(July 2018), 377-388. https://doi.org/10.1016/j.compedu.2018.10.001

Kyewski, E., \& Krämer, N. C. (2018). Computers \& Education To gamify or not to gamify? An experimental fi eld study of the in fl uence of badges on motivation, activity, and performance in an online learning course. Computers \& Education, 118(April 2017), 25-37. https://doi.org/10.1016/j.compedu.2017.11.006.

Maher, Y., Moussa, S. M. and Khalifa, M. E. Learners on Focus: Visualizing Analytics through an Integrated Model for Learning Analytics in Adaptive Gamified E- Learning. IEEE Access, Oct 2020, Print ISSN: 2169-3536, Online ISSN:2169-3536, DOI: 10.1109/ACCESS.2020.3034284.

Owston, R., \& York, D. N. (2018). The nagging question when designing blended courses: Does the proportion of time devoted to online activities matter? Internet and Higher Education, 36(September 2017), 22-32. https://doi.org/10.1016/j.iheduc.2017.09.001

Petri, G., \& Wangenheim, C. G. Von. (2017). How games for computing education are evaluated? A systematic literature review. Computers \& Education. https://doi.org/10.1016/j.compedu.2017.01.004

Phobun, P., \& Vicheanpanya, J. (2010). Adaptive intelligent tutoring systems for e-learning systems.

Procedia - Social and Behavioral Sciences, 2(2), 4064-4069.

https://doi.org/10.1016/j.sbspro.2010.03.641

Shabana, B. T. (2019). GIS Utilization for Strategic Planning Service Delivery Based on Service: Location, Time, And Type; A Case Study: 1st Primary Schools' Strategic Planning in Mansoura City. International Journal of Intelligent Computing and Information Sciences, 19(2), 13-24.

Simões, J., Redondo, R. D., \& Vilas, A. F. (2013). A social gamification framework for a K-6 learning platform. Computers in Human Behavior, 29(2), 345-353. https://doi.org/10.1016/j.chb.2012.06.007

Soflano, M., Connolly, T. M., \& Hainey, T. (2015). An application of adaptive games-based learning based on learning style to teach SQL. Computers and Education, 86, 192-211. https://doi.org/10.1016/j.compedu.2015.03.015

Tsai, F. H., Tsai, C. C., \& Lin, K. Y. (2015). The evaluation of different gaming modes and feedback types on game-based formative assessment in an online learning environment. Computers and Education, 81, 259-269. https://doi.org/10.1016/j.compedu.2014.10.013

Tseng, J., Cheng, Y., \& Yeh, H. (2019). Computers \& Education How pre-service English teachers enact TPACK in the context of web-conferencing teaching: A design thinking approach. Computers \& Education, 128(June 2018), 171-182. https://doi.org/10.1016/j.compedu.2018.09.022 
Wang, S. L., \& Wu, C. Y. (2011). Application of context-aware and personalized recommendation to implement an adaptive ubiquitous learning system. Expert Systems with Applications, 38(9), 1083110838. https://doi.org/10.1016/j.eswa.2011.02.083

Yang, Y. T. C. (2012). Building virtual cities, inspiring intelligent citizens: Digital games for developing students' problem solving and learning motivation. Computers and Education, 59(2), 365-377. https://doi.org/10.1016/j.compedu.2012.01.012

Yip, J., Wong, S., Yick, K., Chan, K., \& Wong, K. (2019). Computers \& Education Improving quality of teaching and learning in classes by using augmented reality video. Computers \& Education, 128 (April 2018), 88-101. https://doi.org/10.1016/j.compedu.2018.09.01s 